\title{
PERSPECTIVES ON THE USE OF THIN FILMS TECHNOLOGIES IN PRECISION MECHANICS AND MECHATRONICS
}

\author{
Georgeta Ionașcu${ }^{1}$, Elena Manea ${ }^{2}$, Raluca Gavrilă ${ }^{2}$ Edgar Moraru ${ }^{1}$ \\ ${ }^{1}$ Politehnica University of Bucharest \\ 313, Splaiul Independentei, 060042-Bucharest, Romania \\ ${ }^{2}$ National Institute for Research and Development in Microtechnologies \\ 126A, Erou Iancu Nicolae Street, 077190-Bucharest, Romania \\ Emails: georgeta.ionascu@upb.ro,elena.manea@imt.ro,raluca.gavrila@imt.ro, edgar.moraru@upb.ro
}

\begin{abstract}
It is well known the high technological importance of the thin films in science and technique fields with major advances. The paper presents, in this context, the modern methods of thin films deposition and their perspectives of use in precision mechanics and mechatronics.
\end{abstract}

Keywords: Thin Films Technologies, Precision Mechanics, Mechatronics.

\section{Introduction}

Thin films have a wide applicability in many fields of science and technology - optics, microelectronics, high frequency electronics, optoelectronics, computers and automations, micromechanics and so on, due to the following advantages: advanced degree of miniaturization and integration; improve of products performance; superior capitalization of materials, energy and incorporated labour; obtaining of new properties and functional principles for the used materials; conservation of rare materials and, last but not least, ecological considerations by reducing the outlet flow of waste liquids / gases and reducing power consumption.

Continuous monoatomic thick materials, as well as methods for manufacturing monomolecular films are known now.

The typical thickness of thin films is $1 \mu \mathrm{m}$. Over $5 \mu \mathrm{m}$ thickness, the optical, electric and magnetic properties of bulk materials are already reached.

Generally, the physical and structural properties of thin layers are similar to those of bulk material. But there are also differences or new features may appear, for example new structural patterns, controlled through thickness and growth mechanism.

In the thin film technology, precision mechanics and mechatronics have a substantial contribution in matters related to materials, processes for obtaining, processing and finishing the substrate, specific working devices for the deposition and configuration stages, thickness control or measuring of other properties of interest [1].

Regarding the uses of thin film structures in precision mechanics and mechatronics, the tendency is to enrich / complete the constructive solutions with microstructures made with materials and technologies specific to microelectronics and micromechanics. In this context, the micro-electromechanical systems (MEMS) or micro mechatronic devices, represent the integration of mechanical elements, sensors, actuators and electronics on a common substrate, a silicon chip only a few millimeters processed by microfabrication technologies [2].

Important aspects of the deposition methods, classifications and choosing criteria, the main methods and their characteristics, as well as perspectives of use in the mentioned fields, are discussed below.

\section{Classification of Thin Film Deposition Methods}

Due to the high technological importance of thin films, a wide variety of deposition methods is currently available. The complexity of the processes involved in these technologies has meant that some methods can be included in one or more categories depending on the classification criterion adopted.

Thus, according to Chapman and Anderson [3, 4], chemical vapor deposition methods are considered chemical methods, and physical vapor deposition methods (evaporation, ion plating, and sputtering) are considered sputtering processes. The situation becomes confusing when reactive and activated reactive evaporation or reactive ion plating are classified as chemical vapor deposition processes, considering that a chemical reaction is involved and neglecting that the reactants are, in addition to 
volatile gases or liquids, and evaporated metal atoms.

In opposition to chemists, physicists Schiller and others [5] include chemical vapor depositions, along with physical ones, in the category of vacuum depositions.

A different classification, which considers the structure and properties of the deposited layers, influenced by the parameters of the deposition process, is provided by Bunshah et al. [6]. Deposition methods are classified according to the size of the species being deposited - atoms / molecules, liquid or solid macroparticles, liquid or solid material.

For atomic deposition processes, the source of the deposition atoms is represented, for example by thermally vaporized or vacuum sputtered atoms (evaporation and vacuum sputtering), chemical species vaporized in a carrier gas (chemical vapor deposition) or ionic species in electrolyte (electrochemical deposition). In low energy processes, the deposition species reach the surface of the substrate, migrate on the surface to the nucleation positions where condense and grow, forming a continuous layer. The nucleation and the growth of the condensed species essentially determine the crystallography and the microstructure of the obtained film.
A high concentration of structural defects results, if the atoms do not reach the configurations characterized by a minimum of potential energy. At other times, the deposition atoms react with the substrate material and form a complex interfacial region. This aspect is found especially in high energy deposition processes, to which the deposition particles react with / or penetrate the surface of the substrate.

Given the above, the authors consider that a rational criterion for classifying deposition methods is the thin film formation environment (Fig.1), which has a decisive role in the adoption and establishment of the basic materials (sources), the parameters of the deposition, the composition and the structure of the thin film [1]. The deposition methods indicated allow the obtaining of layers formed by atoms, molecules, ions or their agglomerations.

of interest for the precision mechanics and mechatronics are also the layers of organic polymers, emulsions and pastes, mechanically deposited (serigraph printing, centrifugation, casting, lamination), thermally (extrusion or casting of molten material) or by sputtering (mechanically, electrostatically) [7].

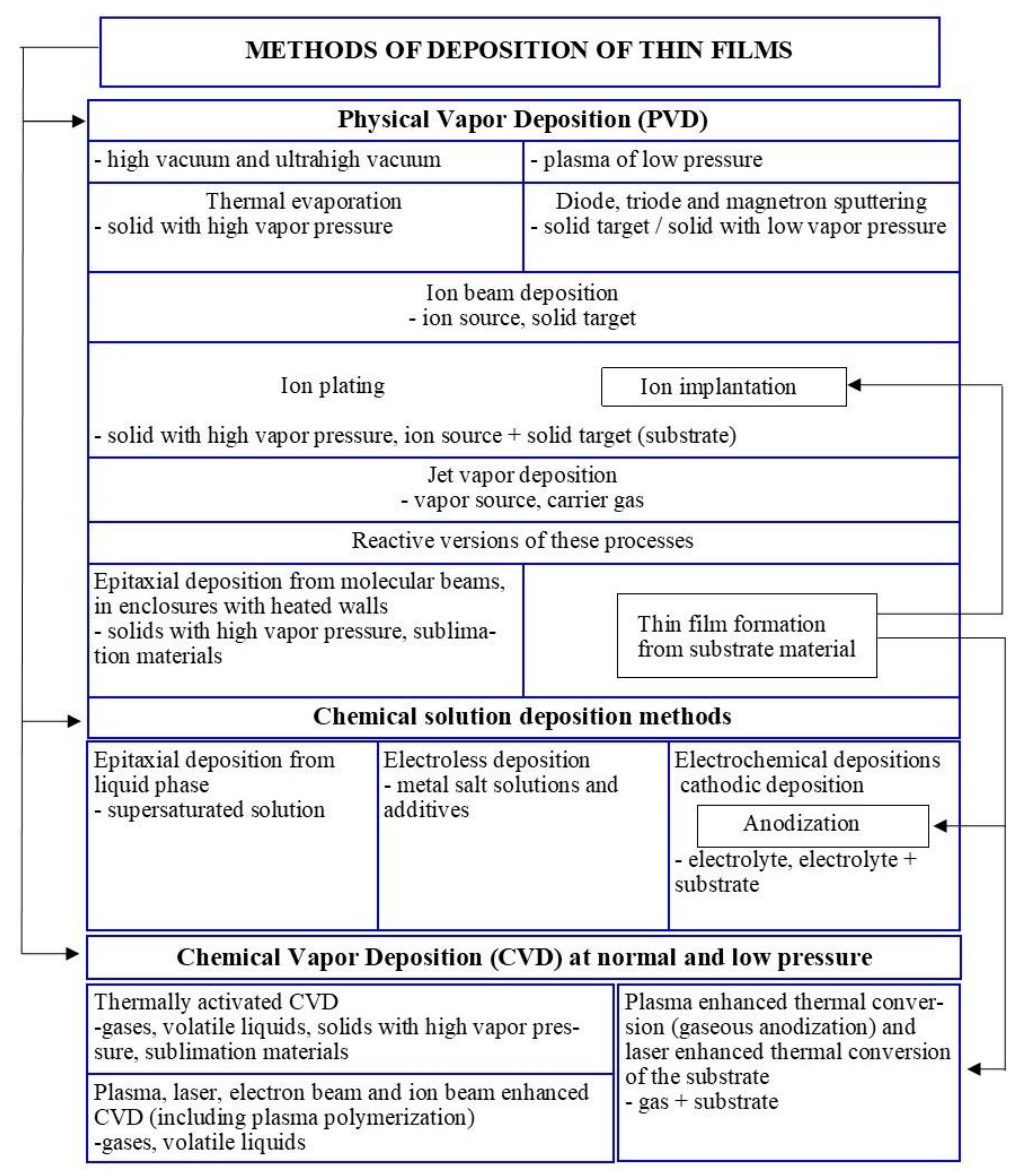

Figure 1. Classification of deposition methods according to the thin film preparation environment (atomic deposition processes) 


\section{Criteria for Choosing the Deposition Methods}

Each deposition method has advantages and disadvantages.

The choice of a certain deposition process is made depending on the following factors:

- Requirements for the material and properties of the thin film. The purity of the material influences the content of impurities in the film. For known material characteristics and well-controllable geometries of the layer-substrate composite, the functional operating properties (adhesion to the substrate, mechanical and chemical resistance, degree of solubility to atmospheric agents etc.) of the deposited layer are decisively influenced by the process parameters (working environment, deposition speed, substrate temperatures etc.);

- limiting the substrate temperature and the compatibility of the deposition method with the processing stages before or after the deposition;

- the penetration power or the capacity of uniform coverage of the parts with complex shapes and hard to reach surfaces;

- the necessary equipment and its cost;

- ecological considerations;

- abundance of deposition material in nature.

Table 1 presents some of the important characteristics of widely used atomic deposition processes.

Table 1. Characteristics of some processes of atomic deposition

\begin{tabular}{|c|c|c|c|c|c|}
\hline Characteristics & Evaporation & Ion plating & Sputtering & $\begin{array}{c}\text { Chemical } \\
\text { Vapor } \\
\text { Deposition }\end{array}$ & $\begin{array}{l}\text { Electrochemical } \\
\text { deposition }\end{array}$ \\
\hline $\begin{array}{l}\text { The mechanism of } \\
\text { producing the } \\
\text { deposition species }\end{array}$ & $\begin{array}{l}\text { Thermal } \\
\text { energy }\end{array}$ & $\begin{array}{l}\text { Thermal } \\
\text { energy }\end{array}$ & $\begin{array}{c}\text { Kinetic } \\
\text { moment } \\
\text { transfer }\end{array}$ & $\begin{array}{l}\text { Chemical } \\
\text { reaction }\end{array}$ & $\begin{array}{c}\text { Solution } \\
\text { deposition }\end{array}$ \\
\hline $\begin{array}{c}\text { The deposition } \\
\text { rates }\end{array}$ & $\begin{array}{l}\text { High and very } \\
\text { high: } \\
\text { typically, } 1-2 \\
\mu \mathrm{m} / \mathrm{min} ; \\
\text { maximum } 75 \\
\mu \mathrm{m} / \mathrm{min} .\end{array}$ & $\begin{array}{l}\text { Medium to } \\
\text { very high: } \\
\text { typically, } \\
0.01-1 \\
\mu \mathrm{m} / \mathrm{min} ; \\
\text { maximum } \\
25 \mu \mathrm{m} / \mathrm{min}\end{array}$ & $\begin{array}{c}\text { Low to } \\
\text { medium: } \\
\text { typically, } 0.01 \\
\mu \mathrm{m} / \mathrm{min}, \\
\text { excepting the } \\
\text { pure metals } \\
\text { (for example, } \\
\mathrm{Cu}-1 \\
\mu \mathrm{m} / \mathrm{min} \text { ). }\end{array}$ & $\begin{array}{c}\text { Medium: } 0.02- \\
0.25 \mu \mathrm{m} / \mathrm{min} \text {, } \\
\text { higher in the } \\
\text { plasma and } \\
\text { particles beam } \\
\text { enhanced } \\
\text { processes. }\end{array}$ & $\begin{array}{c}\text { Medium to very } \\
\text { high: } 0.01-100 \\
\mu \mathrm{m} / \mathrm{min}\end{array}$ \\
\hline $\begin{array}{c}\text { The deposition } \\
\text { species }\end{array}$ & $\begin{array}{l}\text { Atoms and } \\
\text { ions }\end{array}$ & $\begin{array}{l}\text { Atoms and } \\
\text { ions }\end{array}$ & Atoms and ions & Atoms & Ions \\
\hline $\begin{array}{l}\text { The uniformity of } \\
\text { covering the plane } \\
\text { substrates of big } \\
\text { sizes }\end{array}$ & $\begin{array}{l}\text { Depending on } \\
\text { geometry of } \\
\text { the } \\
\text { evaporation } \\
\text { system }\end{array}$ & Good & Good & $\begin{array}{l}\text { Depending on } \\
\text { reactor } \\
\text { geometry, } \\
\text { pression and } \\
\text { temperature of } \\
\text { work }\end{array}$ & Good \\
\hline $\begin{array}{c}\text { The penetration } \\
\text { power for: } \\
\text { a.substrates of } \\
\text { complex shape } \\
\text { b.small and clogged } \\
\text { holes }\end{array}$ & $\begin{array}{l}\text { a. Poor, } \\
\text { because of the } \\
\text { geometric } \\
\text { shading } \\
\text { b. Poor }\end{array}$ & $\begin{array}{l}\text { a. Good, but } \\
\text { non } \\
\text { uniform } \\
\text { thickness } \\
\text { b. Poor }\end{array}$ & $\begin{array}{l}\text { a. Good, but } \\
\text { non uniform } \\
\text { thickness } \\
\text { b. Poor }\end{array}$ & $\begin{array}{l}\text { a. Good } \\
\text { b. Limited }\end{array}$ & $\begin{array}{l}\text { a. Depending on } \\
\text { the electrodes } \\
\text { shape and } \\
\text { position } \\
\text { b. Limited }\end{array}$ \\
\hline Metals deposition & Yes & Yes & Yes & Yes & Yes, but limited \\
\hline Alloys deposition & Yes & Yes & Yes & Yes & Quite limited \\
\hline $\begin{array}{c}\text { Deposition of } \\
\text { refractory } \\
\text { compounds }\end{array}$ & Yes & Yes & Yes & Yes & Limited \\
\hline $\begin{array}{c}\text { Energy of the } \\
\text { deposition species }\end{array}$ & $\begin{array}{c}\text { Low: } \\
0.1 \text { to } 0.5 \mathrm{eV}\end{array}$ & $\begin{array}{l}\text { May be } \\
\text { high: } 1 \text { to } \\
100 \mathrm{eV}\end{array}$ & $\begin{array}{l}\text { May be high: } \\
1 \text { to } 100 \mathrm{eV}\end{array}$ & $\begin{array}{l}\text { May be high in } \\
\text { the plasma and } \\
\text { particles beam } \\
\text { enhanced } \\
\text { processes }\end{array}$ & May be high \\
\hline $\begin{array}{c}\text { The substrate / } \\
\text { film bombardment }\end{array}$ & Normally, not & Yes & $\begin{array}{l}\text { Yes, or not, } \\
\text { depending on }\end{array}$ & Possible & Not \\
\hline
\end{tabular}




\begin{tabular}{|c|c|c|c|c|c|}
\hline $\begin{array}{c}\text { by the ions of an } \\
\text { inert gas }\end{array}$ & 年 & $\begin{array}{c}\text { geometry of } \\
\text { the sputtering } \\
\text { system }\end{array}$ & Yes & Yes & Not \\
\hline $\begin{array}{c}\text { Perturbation of the } \\
\text { growth interface }\end{array}$ & Normally, not & Yes & Not \\
\hline $\begin{array}{c}\text { External heating of } \\
\text { the substrate } \\
\text { during deposition }\end{array}$ & Normally, yes & Yes, or not & Generally, not & Yes & Net \\
\hline
\end{tabular}

\section{Conclusions}

Both categories of methods, physical and chemical, are competitive and complementary. They are continuously improved, in order to extend their use to the new materials and technologies required by the production of microstructures.

The importance of these methods derives from the versatility that allows the preparation of any material, the possibility of obtaining epitaxial layers, as well as the ability to make industrial scale deposits with uniform thickness and composition, having properties suitable for the desired application, controlled by thickness, structure and doping impurities. The possibilities of chemical methods for deposition in the solution should not be underestimated either, because they often represent technological solutions for much cheaper realization.

The multilayer structures and the extremely small dimensions of the ultra miniaturized geometries impose severe requirements on the deposition processes: the reduction of the process temperatures, increasing the degree of conformity of the coating of the steps on substrate, decreasing the number of process-induced defects [8]. The importance of deposition methods at low temperatures and low pressure will increase.

The upper stage of miniaturization and integration, nanotechnology offers techniques for manufacturing and measuring structures at the atomic and molecular level.

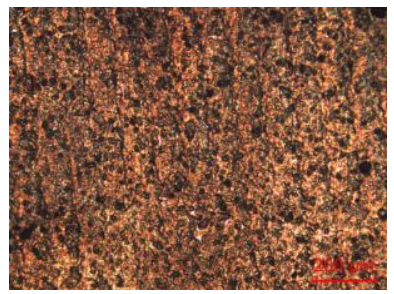

$\mathrm{Cu}$ continuous layer Optical microscope images

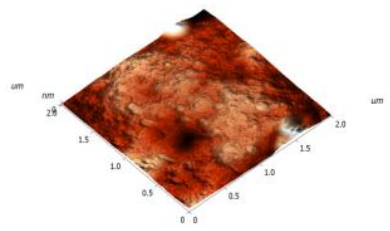

Sn $2 \mu \mathrm{m}$ (scanning area) 3D

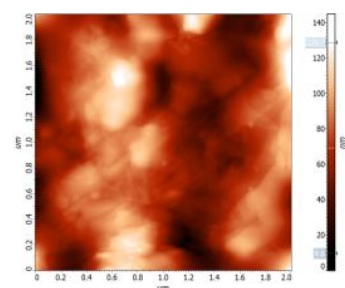

Cu $2 \mu \mathrm{m}$ (scanning area) 2D topo

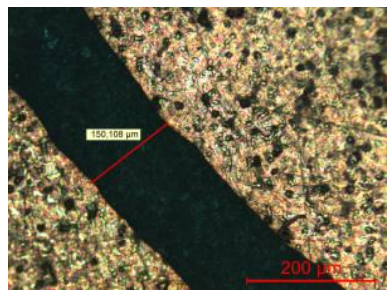

$\mathrm{Cu}$ layer with a photo etched pathway

Optical microscope images

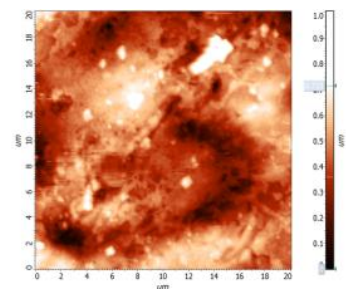

Sn $20 \mu \mathrm{m}$ (scanning area) 2D

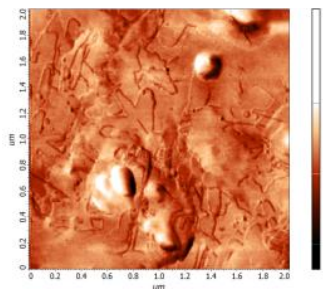

Cu $2 \mu \mathrm{m}$ (scanning area) 2D phase

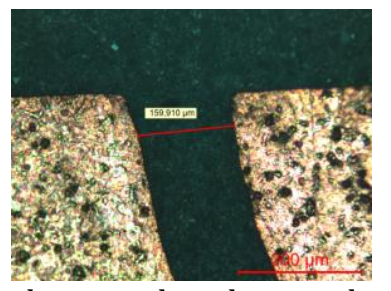

$\mathrm{Cu}$ layer with a photo etched pathway

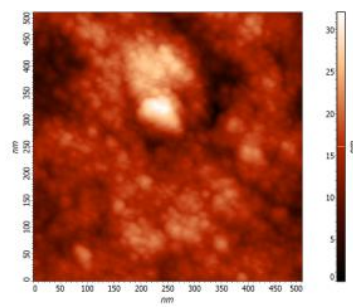

Sn $500 \mathrm{~nm}$ (scanning area) 2D

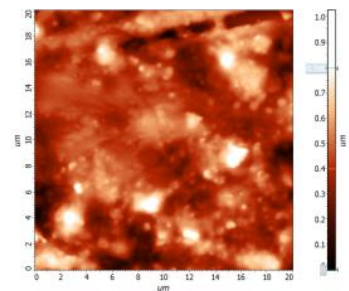

Cu $20 \mu \mathrm{m}$ (scanning area) 2D
AFM images

Figure 2. Images of microstructures viewed at optical microscope and atomic forces microscope (AFM) 
The fundamental concept of nanotechnology arises from the prediction that the precision required in materials processing will reach the extreme level of the order of magnitude of $1 \mathrm{~nm}$, as long as the distance of $0.3 \mathrm{~nm}$ between the atoms of a lattice represents the resolution limit of measurable length in solid materials. In this context, new generations of microscopes have appeared, that can follow the contours of a surface with atomic resolution in all three directions of measurement. In Fig. 2, there are presented the results of the measurements of some structures using optical microscope and microscope with atomic forces (AFM microscope), on some metallic layers of copper $(\mathrm{Cu})$ and tin (Sn) chemically and electrochemically deposited on alumina substrate (alpha-corundum, $\alpha$ Al203), with thickness of 1 - 10 (15) $\mu \mathrm{m}$.

Finally, the last stage of the controlled miniaturization regarding the pattern of the obtained structures, is the manipulation, modification, deposition or insertion of individual molecules on the surface of a previously prepared substrate. Interesting applications refer to the field of molecular sensors and biomolecular electronic devices.

\section{References}

[1] G. Ionascu, Utilization of the Thin Film Structures Technologies in Precision Engineering and Mechatronics, PRINTECH Publishing House, Bucharest (2004). (in Romanian)

[2] G. Ionascu, Technologies of Microtechnics for MEMS, Cartea Universitara Publishing House, Bucharest (2004). (in Romanian)

[3] K. D. Leaver, B. N. Chapman, Thin films, Taylor and Francis (1971).

[4] B. Lewis, J.C. Anderson, Nucleation and Growth of Thin Films, London/New York/San Francisco: Academic Press (1978).

[5] S. S. Schiller, U. Heisig, Chr. Korndörfer, G. Beister, J. Reschke, K. Steinfelder, J. Strümpfel, Reactive d.c. high-rate sputtering as production technology, Surface and Coatings Technology, Vol. 33, 1987, 405-423.

[6] R.F. Bunshah, Handbook of Deposition Technologies for Films and Coatings, Noyes Publications, USA (1994).

[7] J.J. Licari, L.A. Hughes, Handbook of Polymer Coatings for Electronics -Chemistry, Technology and Applications (1990).

[8] A. Sandu, L. Bogatu, G. Ionascu, E. Manea, V. Gheorghe, Modeling, simulation and experimental research for MEMS cantilevers of complex geometry, MATEC Web Conf., 290 (2019) 08002 DOI:

https://doi.org/10.1051/matecconf/201929008 002 